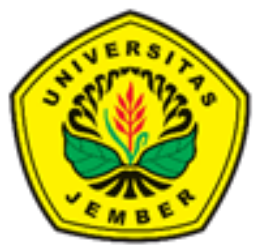

JURNAL MATRAPOLIS

Jurnal Bidang Perencanaan Wilayah dan Kota

Journal Homepage :

https://jurnal.unej.ac.id/index.php/MATRAPOLIS/index

\title{
Daur Ulang Air Limbah Domestik untuk Peningkatan Kualitas Permukiman Kumuh dengan Penggunaan Reaktor Biofilter Anaerob Aerob dan Pengolahan Lanjutan ${ }^{1}$
}

\section{Domestic Waste Water Recycling to Improve Quality of Slums with the Use of Aerobic Anaerobic Reactors and Advanced Treatment}

\author{
Cahyadi Setya Nugraha ${ }^{a}$, Nugroho Chandra Wijaya ${ }^{a}$, Wulida Putri Romadona ${ }^{a}$, Hendi \\ Rengga Akhsani ${ }^{\mathrm{a}}$, Dewi Rizqi Arrochimi ${ }^{\mathrm{a}}$ \\ aProgram Studi S1 Perencanaan Wilayah dan Kota, Jurusan Teknik Sipil, Fakultas Teknik, \\ Universitas Jember, Jl. Kalimantan 37 Jember
}

\begin{abstract}
ABSTRAK
RT 002, RW 003 Kelurahan Bataran, Kecamatan Patrang termasuk kawasan permukiman kumuh sesuai dengan SK Bupati Jember Nomor 188.45/ 338/1.12/ 2016 Tentang penetapan lokasi Lingkungan Perumahan dan Permukiman Kumuh Perkotaan di Kabupaten Jember. Salah satu upaya dalam penanganan permukiman kumuh di Kota Jember adalah dengan adanya Rencana Pencegahan dan Peningkatan Kualitas Permukiman Kumuh Perkotaan atau RP2KP-KP. Terdapat tiga rencana pembangunan yang diterapkan di RT 002, RW 003 Kelurahan Baratan yaitu perbaikan kondisi rumah, pembangunan TPS dan pembangunan MCK. Program pembangunan MCK yang telah dilaksanakan di RT 002 RW 003 Kelurahan Baratan pada kondisi eksistingnya tidak dapat digunakan oleh masyarakat ketika musim kemarau karena tidak adanya pasokan air. Pengguaan reaktor biofilter anaerob aerob dan pengolahan lanjutan dapat memenuhi kebutuhan air dalam program pembangunan MCK di Kelurahan Baratan. Metode dalam perencanaan ini dilakukan secara kuantitaitf dan kualitatif. Metode kuantitatif dilakukan dengan menghitung kebutuhan air serta buangan limbah yang dihasilkan, sedangkan kualitatif dilakukan dengan studi literature terkait reaktor biofilter anaerob aerob dan pengolahan lanjutan serta dilanjutkan pada tahap implementasi desain serta strategi penerapanya. Reaktor anaerob aerob dan pengolahan lanjutan secara umum merupakan teknik daur ulang limbah domestik untuk dirubah menjadi air bersih sehingga dapat dimanfaatkan kembali. Hasil dari adanya pembahsan ini adalah berupa strategi progam yang ditangani oleh Dinas Perumahan Rakyat, Kawasan Permukiman dan Cipta Karya dan organisasi masyarakat setempat. Dengan adanya reaktor biofilter anaerob aerob dan pengolahan lanjutan pasokan air untuk keperluan MCK akan tetap terpenuhi sehingga program pembangunan MCK di RT 002 RW 003 dapat bermanfaat bagi masyarakat sehingga penganganan permukiman kumuh di Kota Jember dapat semakin berkualitas.
\end{abstract}

Kata kunci: Permukiman, Kumuh, Daur Ulang, Biofilter

\begin{abstract}
RT 002, RW 003 Bataran Village, Patrang Subdistrict, including the slum area under the Decree of the Regent of Jember Number 188.45 / 338 / 1.12 / 2016 Regarding the determination of the location of the Urban Slum Housing and Settlement Environment in Jember Regency. One of the efforts in handling slum settlements in Jember City is the existence of a Plan to Prevent and Improve the Quality of Urban Slums or RP2KP-KP. There are three development plans implemented in RT 002, RW 003, Baratan Kelurahan, namely improving
\end{abstract}

\footnotetext{
${ }^{1}$ Info Artikel: Received: 30 Desember 2019, Accepted: 14 Januari 2020
} 
Vol.1, No.1, 2020, p.57-68

housing conditions, building TPS, and building MCK. The MCK construction program that has been carried out in RT 002 RW 003 Baratan Urban Village in its existing condition cannot be used by the community during the dry season due to lack of water supply. The use of aerobic anaerobic biofilter reactors and advanced treatment can meet the water needs in the MCK construction program in Baratan Kelurahan. The method in this planning is carried out quantitatively and qualitatively. The quantitative method is carried out by calculating the need for water and the resulting waste disposal, while the quantitative method is carried out with a literature study related to aerobic anaerobic biofilter reactors and further processing and continued at the design implementation stage and its implementation strategy. Aerobic anaerobic reactors and advanced processing are generally domestic waste recycling techniques to be turned into clean water so they can be reused. The aerobic anaerobic biofilter reactor and the continued processing of water supply for MCK needs will still be fulfilled so that the MCK development program in RT 002 RW 003 can benefit the community so that the handling of slums in Jember City can be of higher quality.

Keywords: Settlement, Slums, Recycling, Biofilter

\section{PENDAHULUAN}

Indonesia merupakan negara berkembang yang berada di posisi ke 4 untuk jumlah penduduk terbanyak di dunia. Meledaknya jumlah penduduk dari tahun ke tahun mengakibatkan timbulnya kawasan atau pemukiman kumuh di Indonesia. Pemukiman kumuh ini dapat di telaah dari tiga segi yaitu segi kondisi fisik, kondisi sosial ekonomi, dan dampak dari kedua kondisi tersebut. Pada kondisi fisik dapat diidentifikasi antara lain kondisi bangunan yang rapat, kualitas kontruksi pemukiman rendah, jaringan jalan yang tidak berpola dan tidak diperkeras, yang terakhir yaitu sanitasi umum dan drainase tidak berfungsi sebagaimana mestinya serta sampah tidak atau belum dikelola dengan baik. Untuk kondisi sosial ekonomi pada pemukiman kumuh rata-rata masyarakatnya memiliki tingkat pendapatan yang rendah, norma sosial yang longgar. Kedua kondisi tersebut mengakibarkan dampak yang buruk seperti kondisi kesehatan yang buruk, sumber pencemaran, sumber penyebaran penyakit dan perilaku menyimpang dan lain-lain. Pemukiman-pemukiman kumuh tersebut sering ditemukan di daerah pinggiran perkotaan di Indonesia. Perkotaan tersebut salah satunya yaitu di Kabupaten Jember yang sudah ditetapkan pada SK kumuh Bupati Jember Nomor 188.45/ 338/1.12/ 2016 Tentang Penetapan lokasi Lingkungan Perumahan dan Permukiman Kumuh Perkotaan di Kabupaten Jember yaitu pada Kecamatan Tempurejo, Kecamatan Kaliwates, Kecamatan Sumbersari, Kecamatan Ambulu dan Kecamatan Patrang yang masih masuk dalam kawasan perkotaan di Kabupaten Jember. Kecamatan Patrang sendiri memiliki 8 kelurahan yaitu Kelurahan Baratan, Kelurahan Bintoro, Kelurahan Banjangsengon, Kelurahan Jember Lor, Kelurahan Gebang, Kelurahan Jumerto, Kelurahan Slawu, dan Kelurahan Patrang. Kecamatan Patrang ini memiliki kawasan kumuh yang sudah ditetapkan yaitu pada Kelurahan Baratan RT 002 RW 003. Karakteristik pemukiman kumuh di Kecamatan Patrang pada Kelurahan Baratan RT 02 RW 03 ini adalah kumuh sedang dengan karakteristik pemukiman pedesaan walaupun wilayah ini masih masuk kedalam wilayah perkotaan Kabupaten Jember.

Menurut penelitian yang diakukan oleh Ivan Agusta F.et.al. (2019) berkesimpulan bahwa prioritas infrastruktur yang dibutuhkan di Kelurahan Baratan adalah prasarana air bersih, pengolahan limbah dan alat pemadam kebakaran. Sumber air bersih yang berada di pemukiman Kelurahan Baratan terdiri dari dua sumber yaitu sumber mata air dan sumur, penyediaan air ini dari sumber mata air didistribusikan melalui jaringan tandon dan perpipaan. Untuk sumber air yaitu sumur terdapat dibeberapa rumah warga setempat. Namun pada musim kemarau, sumber air pada kawasan ini mengalami kekeringan yang mengakibatkan para masyarakat setempat untuk memenuhi kebutuhan air bersihnya dengan membeli kepada pemasok air dengan harga Rp 500/drum. Untuk sanitasi terdapat 
perbaikan dari program KOTAKU yaitu Kota Tanpa Kumuh dalam RP2KPKP dan Kelurahan Baratan RT02 RW 03 masuk kedalam cakupan program tersebut sehingga Pemerintah Kabupaten Jember sebagai nahkoda pelaksanaan memiliki program pembangunan MCK dibeberapa rumah-rumah masyarakat. MCK tersebut sudah selesai dibangun namun beberapa tidak digunakan masyarakat setempat hal ini dikarenakan minimnya pasokan air di MCK tersebut terutama pada musim kemarau. Sehingga program pembangunan MCK yang dilakukan Pemerintah Kabupaten Jember tersebut terkendala dalam hal pemanfaatan oleh masyrakat setempat. Oleh karena itu program lanjutan yang dapat diaplikasikan untuk mengatasi permasalahan seperti kekurangan air pada saat musim kemarau dan mendukung sekaligus membantu program Pemerintah Kabupaten Jember yaitu dengan cara mendaur ulang air limbah. Cara pengolahan air limbah domestic seperti ini telah diteliti dan didokumentasi pada jurnal "Daur Ulang Air Limbah Domestik Kapasitas 0,9 M3 Per Jam Menggunakan Kombinasi Reaktor Biofilter Anaerob Aerob" yang ditulis oleh Wahyu Hidayat Pusat Teknologi Lingkungan, Deputi TPSA, BPP Teknologi

Selain mengatasi permasalahan diatas daur ulang limbah domestic juga merupakan upaya menyelamatkan kelestarian sumber daya air, selain itu hal ini juga dapat sebagai strategi terpadu untuk meningkatkan kualitas lingkungan kawasan Baratan RT02 RW03. Peningkatan kualitas lingkungan ini melalui antara air pengurangan eksploitasi air tanah, peningkatan pengelolaan air limbah termasuk daur ulang air limbah tersebut dan lain-lain. Beberapa factor yang mempengaruhi kemauan masyarakat dalam mengelola energy terbarukan dengan pengelolaan limbah adalah ketersediaan lahan dan tingkat pendidikan yang dimiliki (Listyawati, 2013). Ada beberapa cara pengelolaan air limbah khususnya yaitu air limbah domestic atau rumah tangga dalam rangka mengatasi krisis air bersih dan pencemaran lingkungan salah satunya adalah dengan cara mengolah air limbah rumah tangga secara komunal dan dilanjutkan pengolahan lanjutan daur ulang air limbah tersebut. Oleh karena itu dalam tulisan ini akan membahas tentang daur ulang air limbah rumah tangga atau domestic secara komunal dengan menggabungkan sistem biologis menggunakan reactor biofilter anaerob aerob dengan tujuan menghilangkan polutan organik yang ada pada air limbah domestic tersebut lalu pengolahan lanjutan seperti yang terdiri dari proses oksidasi lalu penyaringan dengan saringan pasir cepat, mangan zeolite, karbon aktif dan untuk meningkatkan kualitas air tersebut pengolahan yang terakhir yaitu dilanjutkan dengan desinfeksi dengan stelisator ultraviolet. Sehingga air limbah rumah tangga atau domestic yang dihasilkan masyarakat Kelurahan Baratan dapat di daur ulang untuk memenuhi kebutuhan air bersih sekaligus membantu berjalannya program KOTAKU yang telah dilaksanakan Pemerintah Kabupaten Jember yaitu pembangunan MCK yang berada di Kelurahan Baratan RT02 RW03 Kecamatan Patrang, Kabupaten Jember.

\section{RUMUSAN MASALAH}

1. Bagaimana proses pengolahan air limbah domestik menggunakan reaktor aerob anaerob dan pengolahan lanjutan?

2. Bagaimana bentuk penerapan desain, strategi, dan program dalam upaya penggunaan reaktor aerob anaerob dan pengolahan lanjutan di RT 002 RW 003 Kelurahan Baratan?

\section{TUJUAN DAN SASARAN}

Tujuan dari penulisan jurnal ini adalah untuk memberi sumbangsi pemikiran dalam konsep pengolahan air limbah domestik agar dapat dimanfaatkan kembali sebagai penyedia air pada program pembangunan MCK di RT002 RW 003 Kelurahan Baratan.

Sasaran dalam penulisan jurnal ini adalah terumuskanya strategi dan program terkait 
Vol.1, No.1, 2020, p.57-68

implementasi penggunaan rekator biofilter aerob anaerob dan pengolahan lanjutan sebagai kesatuan program pembangunan MCK di RT 002 RW 003 Kelurahan Baratan.

\section{METODE}

\section{Pendekatan Penelitian}

Pendekatan dalam kajian ini terdiri dari pendekatan kuantitatif dan kualitatif. Pendekatan kuantitatif dilakukan untuk menghitung kebutuhan air dan buangan air limbah yang dihasilkan oleh masyarakat. Perhitungan kebutuhan air dan buangan air dilakukan untuk menentukan kebutuhan air untuk MCK serta buangan limbah domestik yang dihasilkan untuk didaur ulang di reaktor anarob aerob. Adapun pendekatan kualitatif digunakan untuk menjelaskan dan manganalisis fungsi-fungsi dari penerapan reaktor biofilter anaerob aerob dan tahap pengolahan lanjutan dalam mendaur ulang air limbah domestik agar bisa dimanfaatkan kembali.

\section{Wilayah Studi}

Wilayah studi terdapat di RT 002 RW 003 Kelurahan Baratan, Kecamatan Patrang, Kabupaten Jember. Wilayah studi merupakan salah satu kawasan permukiman kumuh di Kota Jember berdasarkan SK Bupati Jember Nomor 188.45/ 338/1.12/ 2016 Tentang penetapan lokasi Lingkungan Perumahan dan Permukiman Kumuh Perkotaan di Kabupaten Jember.

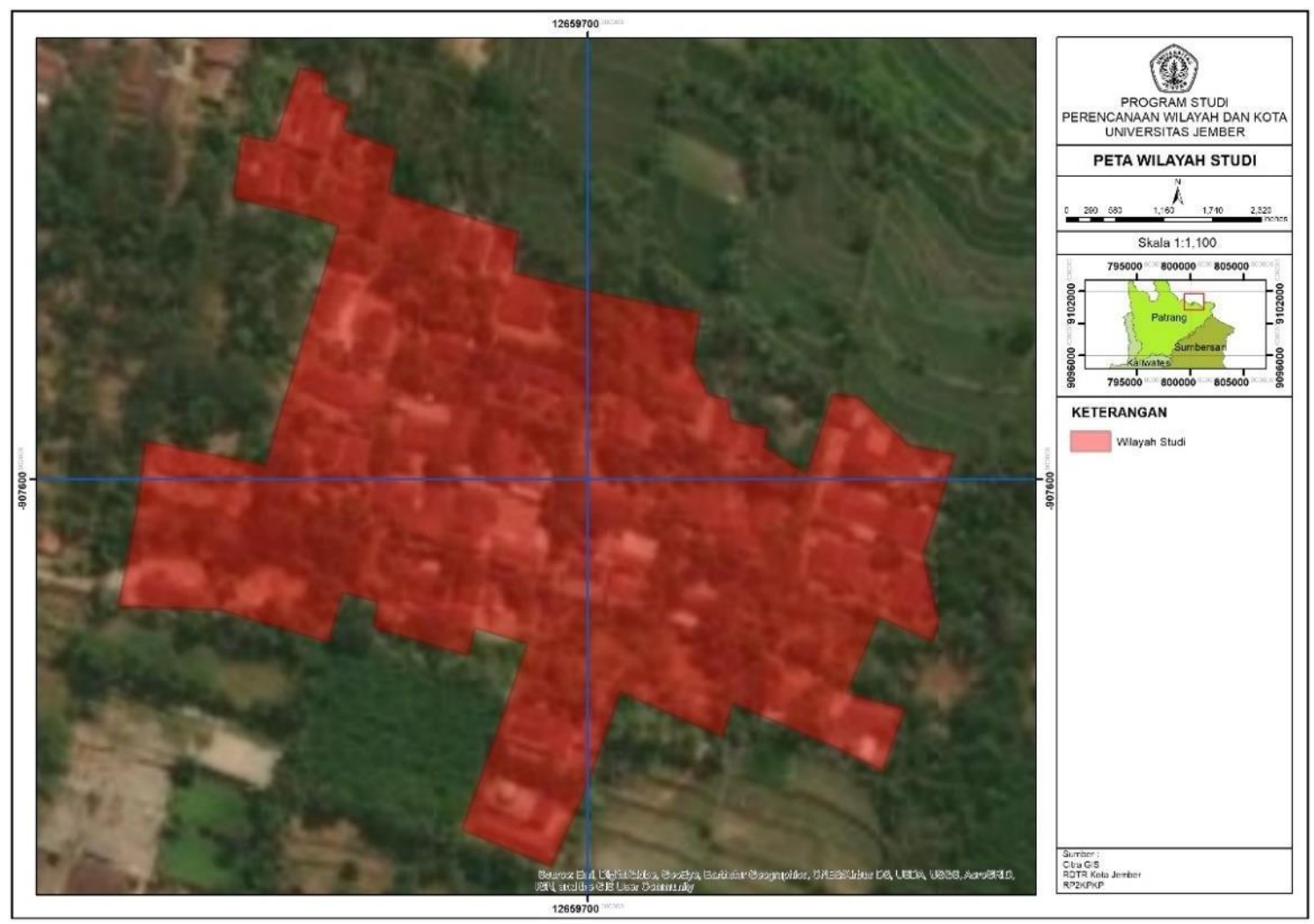

Gambar 1. Peta Wilayah Studi

\section{Metode Perhitungan Kebutuhan Air}

Metode dalam perhitungan kebutuhan air di RT 002 RW 003 Kelurahan Baratan dilakukan berdasarkan jumlah penduduk eksisting. Jumlah penduduk RT 002 RW 003 diasumsikan berjumlah 50 KK sesuai dengan Permendagri No. 7/1983 Tentang Pembnetukan RT dan RW. Kebutuhan air per orang sebesar 601/hari sesuai dengan Keputusan Peraturan 60 Daur Ulang Limbah Domestik 
Pemerintah No. 14/PRT/M/2010 tentang standart pelayanan minimal bidang perkerjaan umum dan penataan ruang. Perhitungan kebutuhan air terdiri menjadi tiga kebutuhan mandi, cuci dan kakus.

Kebutuhan Air Bersih : Jumlah penduduk x 60 liter

Kebutuhan Air untuk Mandi : Jumlah penduduk x 20 liter

Kebutuhan untuk Cuci : Jumlah penduduk x 15 liter

Kebutuhan untuk Kakus : Jumlah penduduk x 10liter

\section{Metode Perhitungan Air Limbah Domestik}

Perhitungan air limbah domestik dilakukan untuk mengetahui jumlah keluaran air dair dari hasil mandi, cuci dan kakus. Perhitungan air limbah domestik juga dilakukan untuk mengetahui jumlah air yang akan ditampung di Reaktor Anaerob Aerob. Adapun rumus dari perhitungan keluaran air limbah adalah $70 \%$ dari kebutuhan air bersih.

\section{Alur Pikir Pengerjaan}

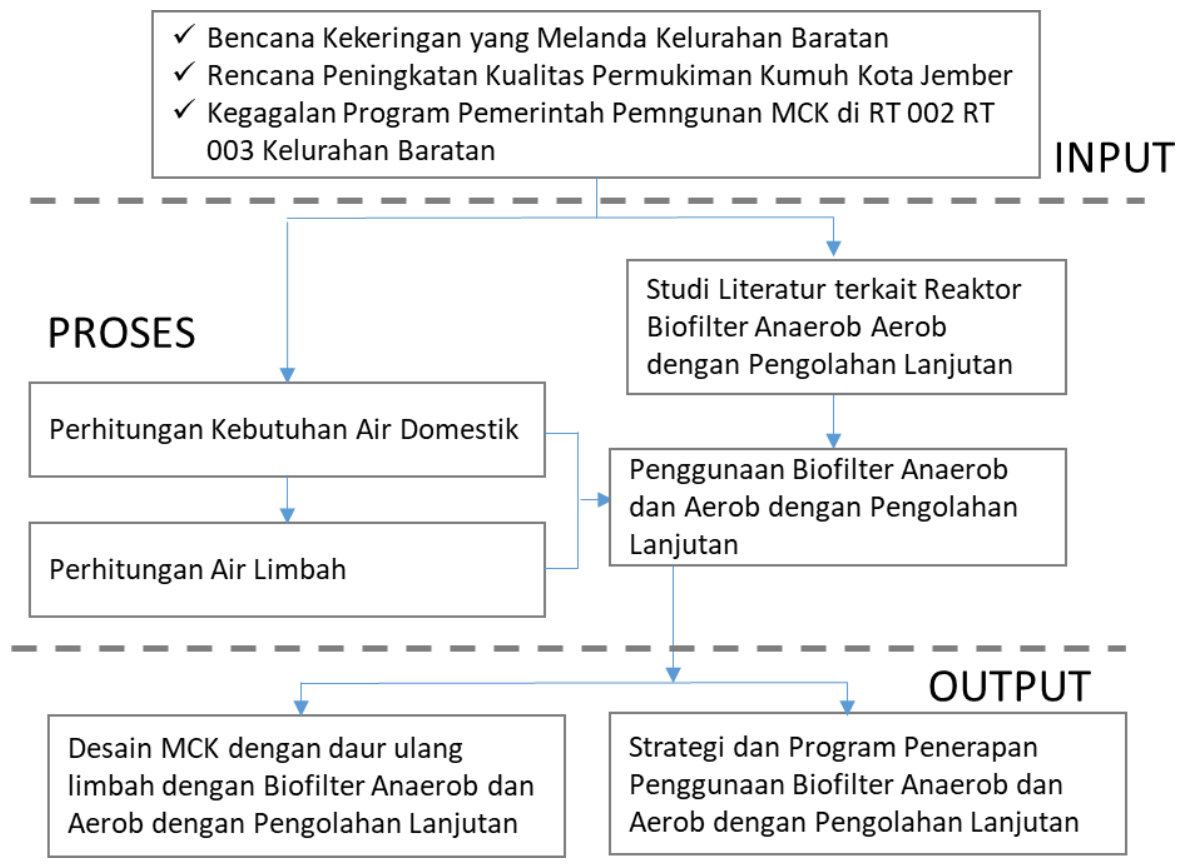

Gambar 2. Alur Pikir Pengerjaan

\section{PEMBAHASAN}

\section{Karakteristik Permukiman Kumuh Kelurahan Baratan}

Secara umum, RT 02 RW 003 Kelurahan Baratan termasuk kedalam wilayah administrasi Kecamatan Patrang yang merupakan wilayah Perkotaan Jember. Permukiman kumuh RT 002 RW 003 Kelurahan Baratan memimiliki luas mencapai 0,21 Ha (SK Kumuh Bupati Nomor 188.45/338/1.12.2016) dengan karakteristik permukiman yang terletak di lereng perbukitan dengan suasana pedesaan. Permasalahan utama permukiman ini sebelum adanya penanganan dari pemerintah adalah tidak tercukupinya kebutuhan air bersih, MCK yang tidak sesuai standart, jaringan jalan dan drainase yang tidak sesuai standart serta tidak adanya sistem pengelolaan sampah. Berdasarkan hasil survey primer, sampai saat ini program yang telah dilaksanakan meliputi penyeidaan jaringan perpiaan air bersih, pembangunan jalan lingkungan, peningkatan kualitas rumah serta pembangunan MCK. Permasalahan utama yang belum tertangani sampai saat ini adalah ketersediaan pasokan 
Vol.1, No.1, 2020, p.57-68

air bersih. Pada saat musim kemarau masyarakat RT 002 RW 003 Kelurahan Baratan 
memenuhi kebutuhan air minum dengan membeli sedangkan keberadaan MCK tidak dapat dimanfaatkan oleh masyarakat karena tidak adanya pasokan air.

\section{Aspek Teknis Penggunaan Reaktor Biofilter Anaerob-Aerob dan Pengolahan Lanjutan \\ Perhitungan Kebutuhan Air}

Sesuai Permendagri No.7/1983 tentang Pembentukan RT dan RW, setiap RT sebanyakbanyaknya terdiri dari $50 \mathrm{KK}$ untuk kelurahan. Maka pada kelurahan Baratan diasumsikan terdapat $50 \mathrm{KK}$.Untuk dapat mengetahui kebutuhan air maka perlu dilakukan penghitungan air bersih berdasarkan Keputusan peraturan pemerintah No 14/PRT/M/2010 tentang standar pelayanan minimal bidang pekerjaan umum dan penataan ruang kebutuhan air yaitu per orang 60 liter/hari dan SNI 03-2399-2002 tentang Tata cara perencanaan bangunan MCK, dengan hasil sebagai berikut:

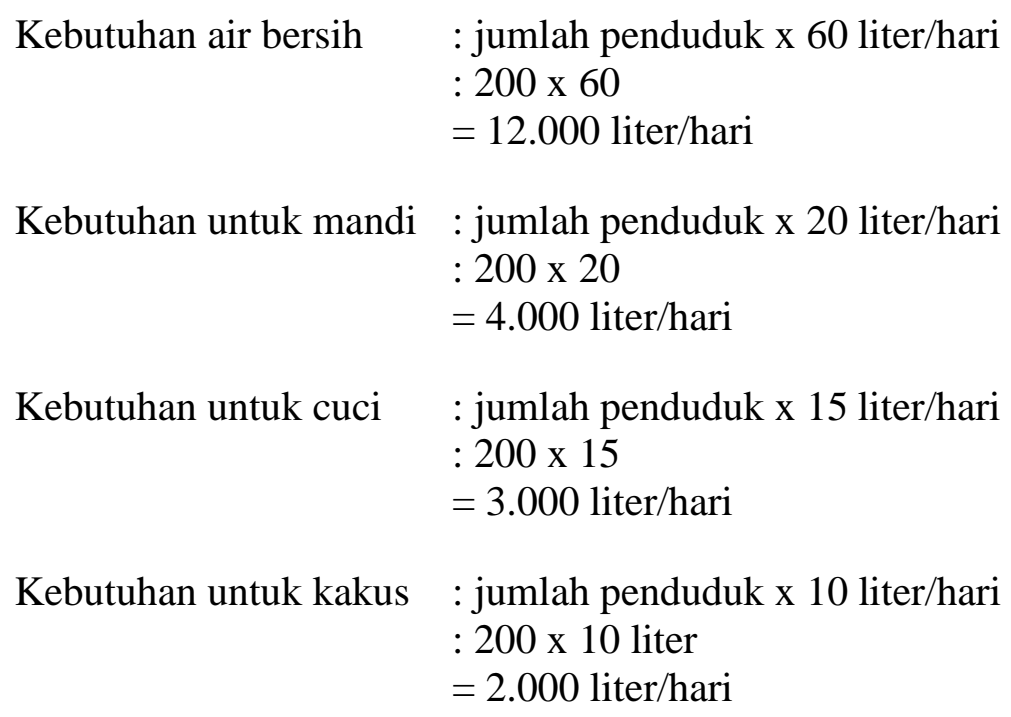

\section{Perhitungan Limbah Domestik}

Air limbah domestik dihitung dari 70\% dari total kebutuhan air bersih, dengan hasil sebagai berikut:

Air limbah : air bersih $\times 70 \%$

$$
\begin{aligned}
& : 12.000 \times 70 \% \\
& =8.400 \text { liter/hari }
\end{aligned}
$$

\section{Pengolahan Air Limbah Domestik dengan Reaktor Biofilter Anaerob-Aerob}

Bersumber dari Wahyu Widayat (2009) Daur Ulang Air Limbah Domestik Kapasitas 0,9 $\mathrm{m}^{3}$ per Jam Menggunakan Kombinasi Reaktor Biofilter Anaerob Aerob dan Pengolahan Lanjutan, proses pengolahan air limbah domestik dengan reaktor biofilter anaerob-aerob terdiri dari beberapa proses sebagai berikut :

\section{Bar Screen}

Proses awal dari pengolahan air limbah hasil pembuangan dari rumah tangga dipisahkan pada bak pengumpul air limbah dengan pelengkap berupa saringan kasar (bar screen). Bar screen merupakan saringan berbentuk batang-batang horizontal dengan jarak antar batang 
Vol.1, No.1, 2020, p.57-68

$10 \mathrm{~cm}$. Sampah padat yang berhasil disaring oleh bar screen selanjutnya akan dibersihkan secara berkala sehingga hasil dari sampah yang telah disaring dapat dibuang di tempat sampah.

\section{Bak Pengendap Awal}

Proses penyaringan yang telah dilalui oleh air limbah pada bar screen selanjutnya dialirkan ke bak pengendap awal dengan cara pengendapan partikel lumpur maupun pasir yang terdapat pada air limbah. Selain itu, bak pengendap awal dapat digunakan sebagai bak pengurai dari senyawa organik yang berupa padatan, pengurai lumour, (sludge digestion) dan penampung endapan (lumpur) serta bak pengontrol laju alir (debit) dan Ruang Anaerob

\section{Ruang Anaerob}

Pada ruang anaerob, air limbah yang telah dipisahkan dari lumpur akan disalurkan pada bak kontaktor anaerob dengan arah aliran dari atas ke bawah dan sebaliknya. Bak kontaktor anaerob harus mengandung media biakan bakteri dengan media yang digunakan dari bambu. Bambu yang digunakan sebagai media dipotong-poting membentuk cincin. Namun media juga dapat menggunakan bahan lainnya seperti kerikil, plastik, PVC, dan batu split. Terkait dengan biaya operasional maka dapat digunakan media biakan bakteri dengan berbahan ringan, kuat, tipis serta memiliki permukaan kontak yang luas yaitu lembaran PVC yang dibentuk menyerupai sarang lebah. Jumlah bak kontaktor anaerob disesuaikan dengan kualitas, kebutuhan serta jumlah air limbah yang dihasilkan untuk dikelolah.

Prinsip kerja bak kontaktor anaerob sebagai berikut.

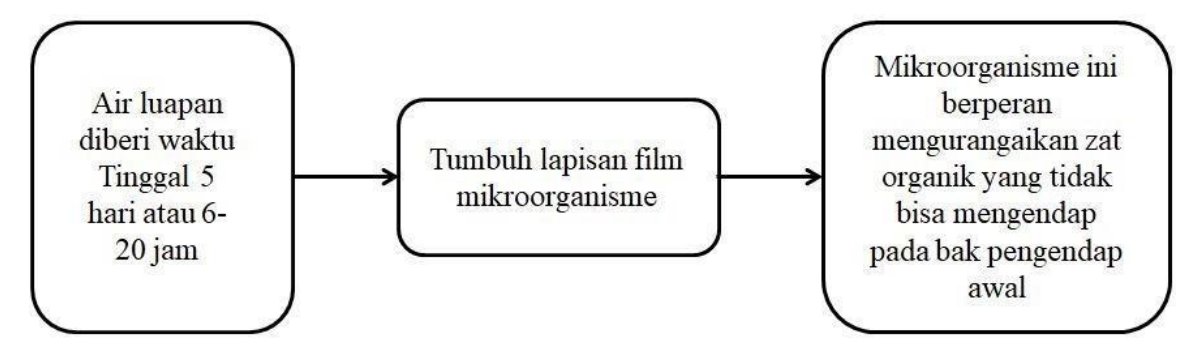

Gambar 3. Alur Kerja Bak Kontaktor Anaerob

Sumber : Diolah dari Wahyu Widayat, 2009

\section{Ruang Aerob}

Pada ruang aerob, Biofilter aerob menghembuskan udara pada air luapan sehingga mikro organisme aerobik yang menempel dan tumbuh pada permukaan media serta menguraikan air limbah yang mengandung zat organik. Media biakan yang dilewati oleh air limbah akan bersentuhan dengan mikro - organisme yang menempel pada permukaan maupun tersuspensi di dalam air. Proses alamiah tersebut membuat penguraian zat organik lebih efisien serta mempercepat proses nitrifikasi sehingga meningkatkan penghilangan ammonia yang terkandung dalam air limbah. Proses penguraian ini dinamakan Aerasi Kontak (Contact Aeration). 


\section{Bak Pengendap Akhir}

Air luapan yang masih mengandung lumpur aktif dengan kandungan mikro-organisme selanjutnya akan dilakukan proses pengendapan dan sebagian akan dipompa kembali masuk ke biofilter aerob dengan menggunakan pompa sirkulasi lumpur.

\section{Bak Khlorinasi}

Air luapan yang mengandung microorganisme patogen akan dialirkan pada bak khlorinasi. Hasil dri pengolahan akhir yang tidak mengandung micro-organisme patogen akan dilakukan proses lanjutan berupa pengolahan air limbah menjadi air bersih.

\section{Daur Ulang Air Limbah Lanjutan}

Secara teknik, hasil air limbah yang telah dilakukan pengolahan pada reaktor biofilter anaerob-aerob tidak dapat digunakan sehingga dilakukan pengolahan lanjutan guna meningkatkan kualitas air bersih dengan proses yang dilakukan sebagai berikut.

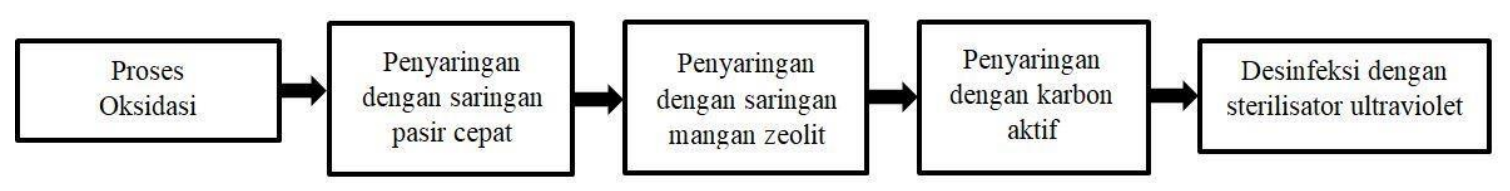

Gambar 4. Proses Daur Air Limbah

Sumber : Diolah dari Wahyu Widayat, 2009

Air limbah rumah tangga hasil proses tersebut dapat ditingkatkan lagi melalui proses oksidasi, penyaringan dengan saringan pasir cepat, penyaringan dengan saringan mangan zeolite, penyaringan dengan karbon aktif, desinfeksi dengan sterilisator ultraviolet. Hasil air dari pengolahan reaktor biofilter anaerob-aerob akan di tampung dalam bak yang selanjutnya yaitu tahap oksidasi dengan mengoksidasi zat besi atau mangan yang ada di dalam air hasil pengolahan air limbah domestik, selain itu juga berfungsi untuk membunuh kuman atau bakteri e coli. Selanjutnya tahap saringan pasir cepat pada proses ini berfungsi untuk menyaring padatan yang berada di air serta oksida besi atau oksida mangan yang terbentuk di dalam tangki reaktor tersebut. Selanjutnya proses saringan mangan zeolit. Proses ini bertujuan menghilangkan zat besi atau mangan yang belum teroksidasi di proses sebelumnya. Selanjutnya proses saringan karbon aktif. Pada proses ini bertujuan untuk menghilangkan polutan mikro yang terdapat pada air contohnya seperti zat organik, deterjen, bau, senyawa dan logam-logam berat lainnya. Tahap terakhir yaitu Sterilisator Ultraviolet pada proses ini bakteri atau mikroorganisme yang ada di air dapat dibunuh secara sempurna.

\section{Desain Implementasi Penggunaan Biofilter Anerob Aerob dan Pengolahan Lanjutan di RT 002 RW 003 Kelurahan Baratan}

Penggunaan biofilter anaerob aerob dan pengolahan lanjutan di arahkan untuk dapat menampung dan mengolah keseluruhan limbah domestik yang terdapat di RT002 RW003 Kelurahan Baratan. Kapasitas satu bioliter anaerob aerob dan pengolahan lanjutan diarahkan maksimal mampu menampung $25 \mathrm{kk} /$ rumah. Oleh karena itu dibutuhkan dua biofilter anaerob aerob dan pengolahan lanjutan untuk keseluruhan KK dengan masing- masing mengolah buangan limbah sebsesar $4.200 \mathrm{~L} / \mathrm{hari}$. 
Vol.1, No.1, 2020, p.57-68

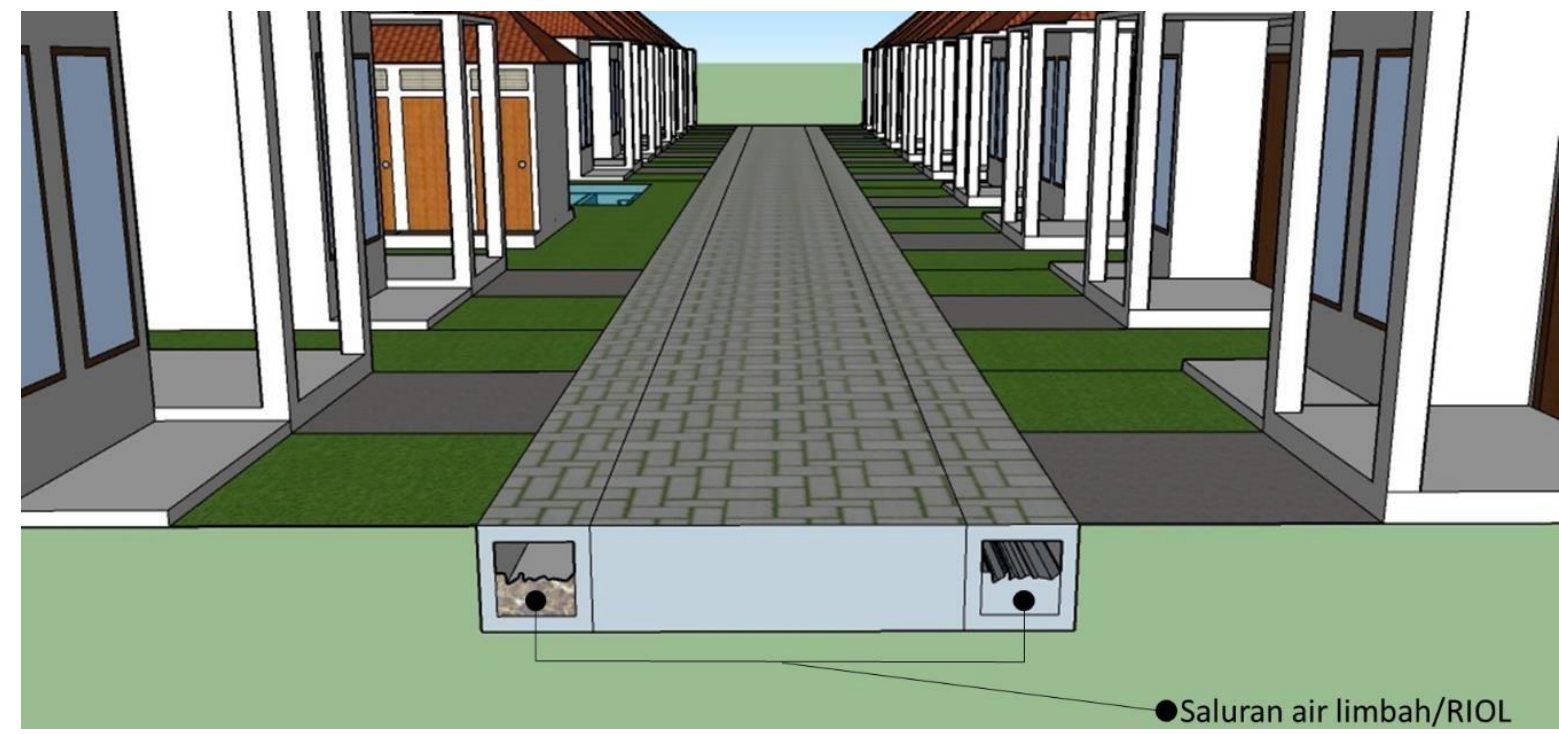

Gambar 5. Saluran Air Limbah/Riol

Air limbah domestik per rumah dialirkan melalui jaringan riol yang direncanakan terdapat dibawah jalan lingkungan RT002 RW003 Kelurahan Baratan. Air limbah berasal dari kegiatan rumah tangga seperti mandi, cuci, kakus dan lainya diarahkan menuju reaktor biofilter anaerob aerob untuk melalui proses pendaur ulangan.
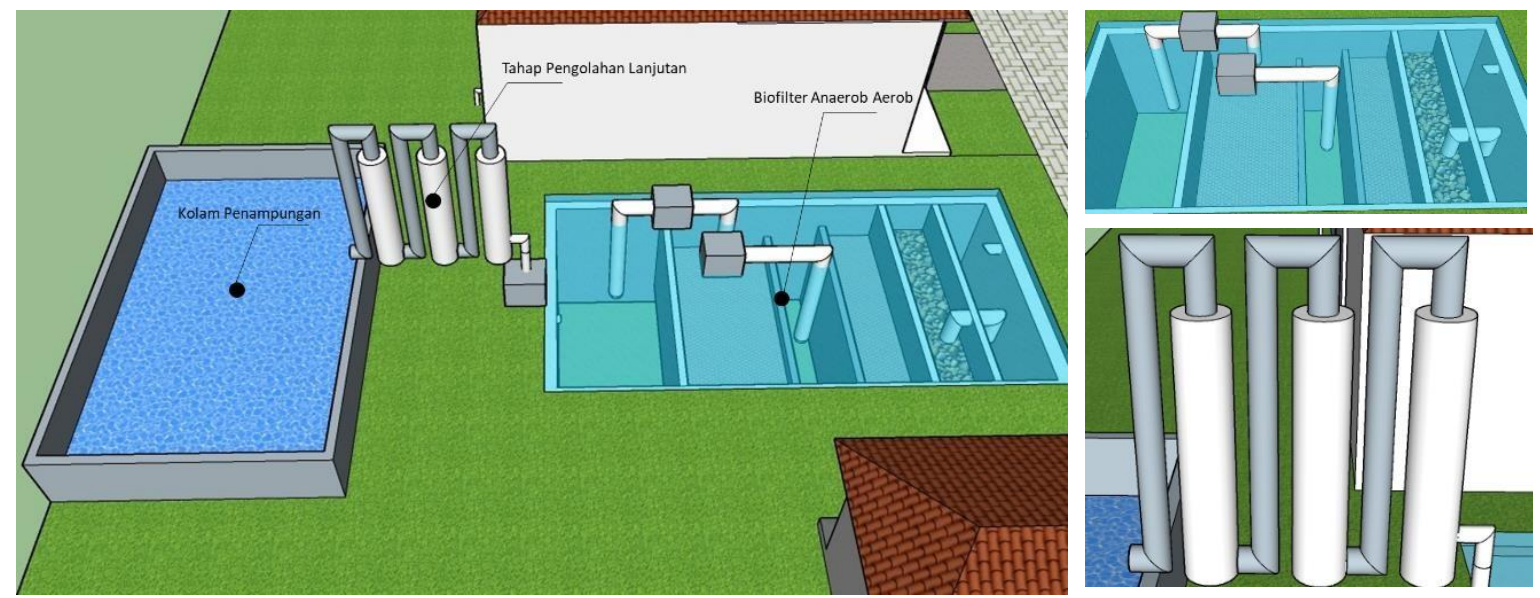

Gambar 6. Rancangan Biofilter Anaerob Aerob dan Pengolahan Lanjutan 


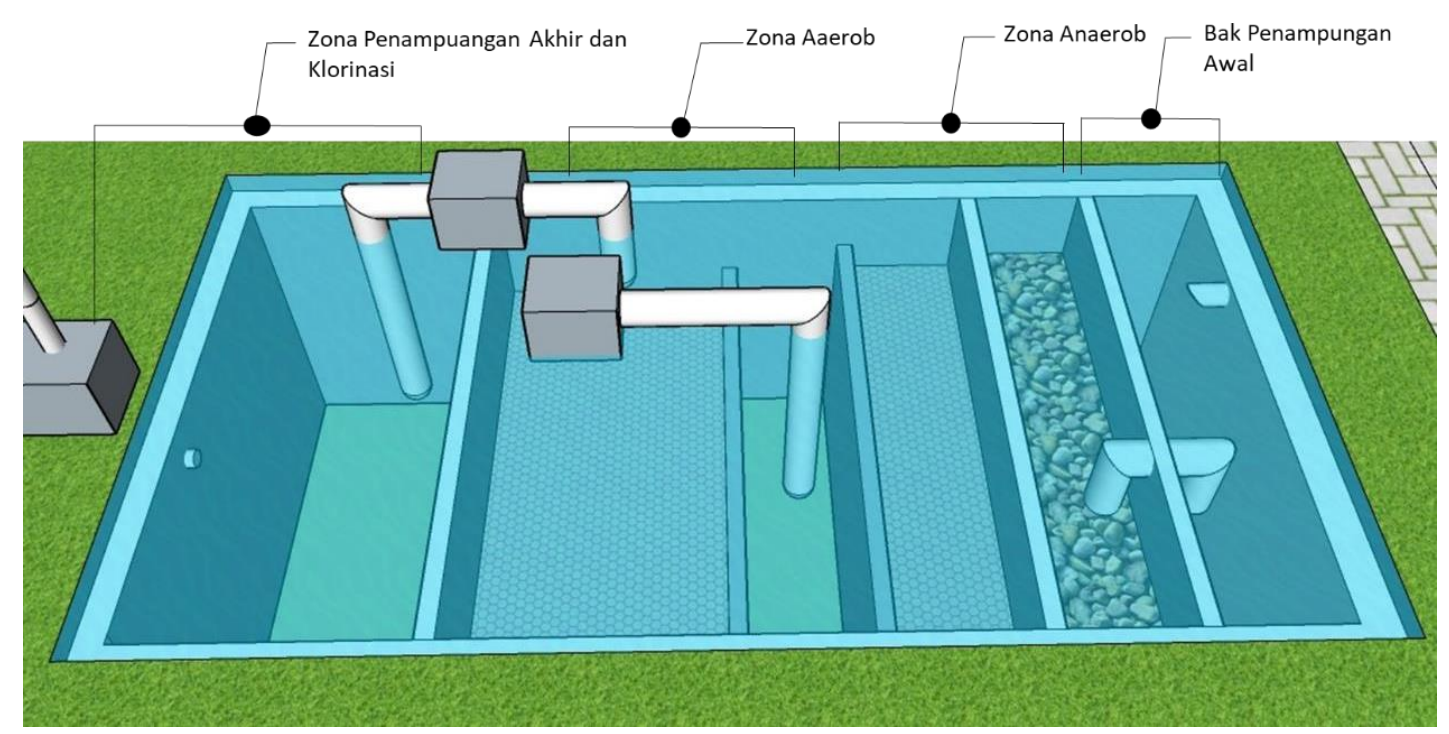

Gambar 7. Reaktor Biofilter Anarob Aerob

Air limbah domestik yang telah menjalani proses pengolahan akan berubah menjadi air bersih yang kemudian ditampung di kolam penampungan. Kolam penampungan ini berfungsi sebagai tempat penampungan air bersih hasil pengolahan sebelum di distribusikan menuju MCK umum dan milik pribadi yang telah dimiliki warga.
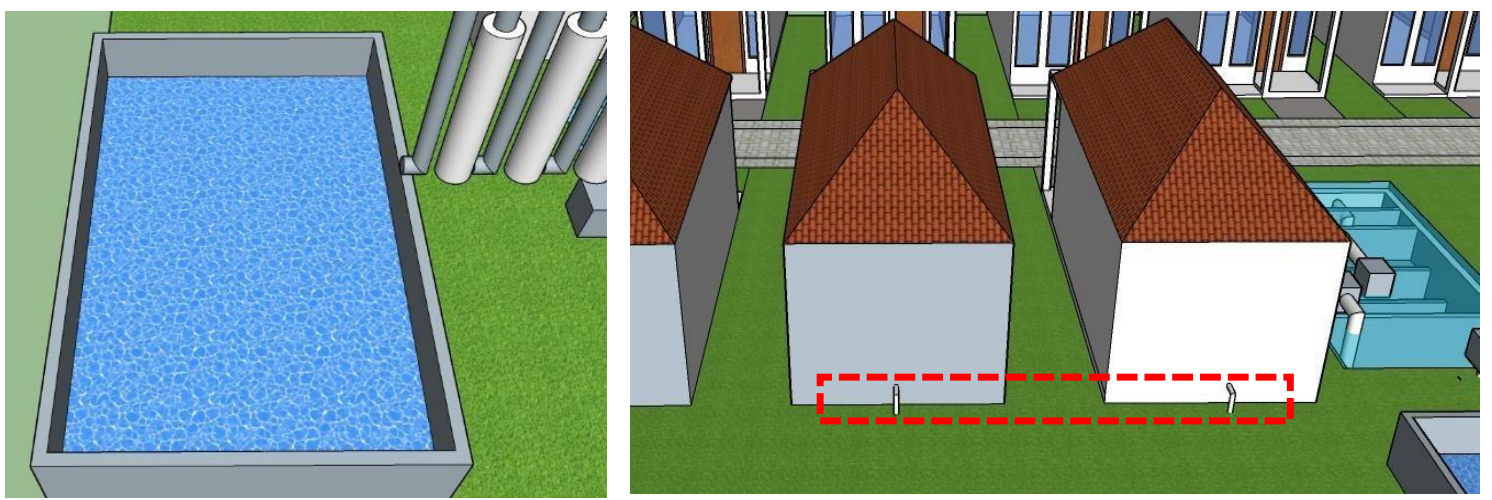

Gambar 8. Kolam Penampungan dan Sistem Distribusi

\section{Strategi dan Program Penerapan}

Upaya penerapan penggunaan reaktor biofilter anaerob aerob dan pengolahan lanjutan di RT 002 RW 003 Kelurahan Baratan secara umum terbagi menjadi dua kelembagaan yaitu milik pemerintah dan kelembagaan secara kemasyarakatan. Kelembagaan pemerintah ditangani oleh Dinas Perumahan Rakyat, Kawasan Permukiman dan Cipta Karya Kabupaten Jember pada Bidang Perumahan dan Permukiman dan Bidang Penyehatan Lingkungan Permukiman. Adapun untuk kelembagaan masyarakat berupa pembentukan kelompok organisasi sebagai pengurus yang mewadahi kelompok maysarakat pengguna dan pemanfaat air dari pengolahan reaktor biofilter anaerob aerob dan pengolahan lanjutan. Rincian program disajikan pada tabel 1. 
Vol.1, No.1, 2020, p.57-68

Tabel 1. Daftar Rincian Program

\begin{tabular}{|c|c|c|c|}
\hline No & Kelembagaan/Dinas & Bidang & Program \\
\hline \multirow[t]{5}{*}{1} & \multirow{5}{*}{$\begin{array}{l}\text { Dinas Perumahan Rakyat, } \\
\text { Kawasan Permukiman dan Cipta } \\
\text { Karya }\end{array}$} & \multirow{2}{*}{$\begin{array}{l}\text { Bidang Perumahan } \\
\text { dan Permukiman }\end{array}$} & Pembangunan Jalan Lingkungan \\
\hline & & & $\begin{array}{lll}\text { Peningkatan } & \text { Kondisi } & \text { Jalan } \\
\text { Lingkungan } & & \\
\end{array}$ \\
\hline & & \multirow{3}{*}{$\begin{array}{l}\text { Bidang Penyehatan } \\
\text { Lingkungan } \\
\text { Permukiman }\end{array}$} & $\begin{array}{l}\text { Penyediaan Sarana } \\
\text { Prasarana Air Bersih }\end{array}$ \\
\hline & & & $\begin{array}{l}\text { Pembangunan Reaktor Biofilter } \\
\text { Anaerob Aerob Dan Pengolahan } \\
\text { Lanjutan }\end{array}$ \\
\hline & & & $\begin{array}{l}\text { Program Pengembangan Kinerja } \\
\text { Pengelolaan Air Limbah } \\
\text { (Pembangunan Mck) }\end{array}$ \\
\hline \multirow[t]{3}{*}{2} & \multirow[t]{3}{*}{ Organisasi Masyarakat } & & Program Bersih Lingkungan \\
\hline & & & Program Edukasi Masyarakat \\
\hline & & & $\begin{array}{lcc}\text { Program } & \text { Pengawasan } & \text { Dan } \\
\text { Penjagaan } & \text { Pengelolaan } & \text { Air } \\
\text { Limbah } & & \end{array}$ \\
\hline
\end{tabular}

Sumber : Rencana, 2019

\section{KESIMPULAN}

RT 002 RW 003 Kelurahan Baratan termasuk kedalam kawasan permukiman kumuh menurut SK Bupati Nomor 188.45/ 338/1.12/ 2016 Tentang penetapan lokasi Lingkungan Perumahan dan Permukiman Kumuh Perkotaan di Kabupaten Jember. Permasalahan utama kekumuhan di lingkungan tersebut disebebkan oleh tidak tercukupinya kebutuhan air bersih, MCK yang tidak sesuai standart, jaringan jalan dan drainase yang tidak sesuai standart serta tidak adanya sistem pengelolaan sampah. Adanya program bantuan dari pemerintah berupa pembangunan MCK tidak dapat dimanfaatakn oleh warga karena terkendala pasokan air yang terbatas karena kekeringan. Penggunaan biofilter aerob anaerob dan pengolahan lanjutan diharapkan mampu mengatasi permasalahn pasokan air untuk kebutuhan MCK.

Tahap pengolahan limbah domestik dengan menggunakan reaktor biofilter anaerob aerob terdiri meliputi proses penyaringan awal, pengendapan, proses anaerob, proses aerob, pengendapan akhir serta proses klorinasi. Adapun pada tahap pengolahan lanjutan agar air dapat berubah menjadi air bersih meliputi tahapan oksidasi, penyaringan tiga tahap, dan desinfeksi dengan ultraviolet. Perumusan strategi dan program dalam perencanaan biofilter aerob anaerob dan pengolahan lanjutan di RT 002 RW 003 Kelurahan Baratan diarahkan terdiri dari dua kelembagaan yaitu pemerintah dan masyarakat. Kelembagaan pemerintah selaku penanggung jawab program pembangunan terdapat pada Dinas Perumahan Rakyat, Kawasan Permukiman dan Cipta Karya pada Bidang Perumahan dan Permukiman dan Bidang Penyehatan Lingkungan Permukiman. Adapun kelembagaan masyarakat berupa pembuatan organisasi yang bertanggung jawab untuk membina lingkungan, edukasi masyarakat, serta pengawasan dan penjagaan pengelolaan air limbah di RT 002 RW 003 Keluraha Baratan. 


\section{SARAN}

1. Perlu adanya perhitungan lebih rinci dengan menggunakan metode-metode yang lebih akurat untuk menghitung kebutuhan air serta keluaran limbah domestik.

2. Perlu adanya studi teknis mengenai perencaan reaktor biofilter anaerob aerob dan pengolahan lanjutan.

3. Perlu adanya pendataan dan perhitungan terkait perencanaan pemasokan air dari hasil pengolahan menuju rumah-rumah warga.

4. Perlu adanya studi mengenai kualitas air yang dihasilkan dari hasil pengolahan reaktor biofilter anaerob aerob dan pengolahan lanjutan.

\section{DAFTAR PUSTAKA}

Farizkha, I. A, Listyawati, RN, Alfiah, R. \& K, D. J., 2019. Identification Of Slum Typologies Based On Priority Infrastructure (Case Studies Jember District). CITIES 2019 INTERNATIONAL CONFERENCE, pp. 1-11.

Kementrian Pekerjaan Umum Dan Perumahan Rakyat Direktorat Pengembangan Kawasan Permukiman. Dokumen RP2KP-KP (Rencana Pencagahan dan Peningkatan Kualitas Permukiman Kumuh Perkotaan) Kabupaten Jember, Jawa Timur. KOTAKU (Kota Tanpa Kumuh).

Listyawati, R.N, C Meidiana \& M Anggraeni. 2013. Pemanfaatan Limbah Kotoran Ternak Sebagai Energi Alternatif Skala Rumah Tangga Di Desa Tegalweru. Jurnal Tata Kota dan Daerah Volume 5, Nomor 2.

Peraturan Menteri Dalam Negeri No. 7/1983 Tentang Pembentukan RT dan RW

Standart Nasional Indonesia 03-2399-2002 tentang Tata cara perencanaan bangunan MCK

Widayat, Wahyu. (2009). Daur Ulang Air Limbah Domestik Kapasitas 0,9 $\mathrm{m}^{3}$ per Jam Menggunakan Kombinasi Reaktor Biofilter Anaerob Aerob dan Pengolahan Lanjutan. Jakarta Pusat. Pusat Teknologi Lingkungan, Deputi TPSA, BPP Teknologi. JAI Vol 5. No. 1. 2009. 